Theories \& Applications, the International Edition

Printed Version: (ISSN 2090-5262)

Online Version: (ISSN 2090-5270)

July 2012, Volume 2, No. 2 Pages (40 - 50)

\title{
Effect of Enrichment Activities on Creativity and the Level of Performance in Motor Expression
}

\author{
Nadia Abdel-Hamid Al-Demerdash*, Amal Mohamed Mefreg**
}

\begin{abstract}
:
The purpose of this study was to design a suggested program of enrichment activities and to know its effect on creativity and the level of performance in motor expression in female students in the 4th grade (teaching branch) at Faculty of Physical Education for girls. The two researchers used the experimental method through the pre and post-measurement design and the research sample included (24) female students who were divided into two equivalent groups to represent the experimental group being under the suggested program and the control group being under the prescribed curriculum of motor expression under the supervision of the two researchers. Data were collected by using motor expression creativity test (prepared by Amal Morsi) and revised by (the two researchers). The results showed that there were statistically significant differences between the pre and post-measurements in the two research groups in the test of creativity in motor expression with its three components towards the post-measurements of the experimental group.
\end{abstract}

Keywords: Enrichment activities, creativity in motor expression, level of performance.

\section{Introduction:}

C teps supporting the application of the program of educational quality assurance and dependence are upgrading the level of the teacher and reviewing his preparation programs. It should be necessary to consider programs of preparing teachers for the academic level as well as upgrading their level and constantly evaluating them within the development of the educational process (1).

Greenfield confirmed that upgrading the academic education in future would be in need of renaissance in the development of teacher's roles, responsibilities and selection (6).

Creativity is the way to the development of human and the progress of the whole world. So, several theoretical studies and researches introduced creativity as it plays a greater importance that represents the vertex of mental

\footnotetext{
* Professor, Deptartment of Motor Expression and Motor Rhythm Training, Faculty of Physical Education for Girls, Helwan University, Egypt.

** Assistant Professor, Deptartment of Motor Expression and Motor Rhythm Training, Faculty of Physical Education for Girls, Helwan University, Egypt.
}

activity leading to distinction that shown in the individual's creative product, represented by producing something new or found new relationships for things previously known (8).

Enrichment programs had a great importance in increasing creativity and motivation in students making them more open to experiences of others and developing their skills to generate ideas and to provide original alternatives to solve problems (15).

Adel Abdulla Mohammed citing from Letgort viewed that flexibility could be an advantage of enrichment as it could be used with all individuals of different mental levels that it could be suitable for the individual of weak or of medium ability and mentally superior individual. Also, it requires improvement in quantity and quality (4).

Modern dance as a branch of motor expression is a creative and innovative art using different and various body movements made by the individual according to his potentials. The philosophy of modern dance stands on giving full freedom to the dancer to express. This freedom appears in the way of the dancer to 
perform and the design presented. It allows the individual to move, to express, to discover and to highlight his talent. The modern dancer is mostly characterized by creativity through developing the individual's mental abilities and motivating abilities of innovation, imagination and visualization. Moreover, it develops skills of recalling and memorizing and the ability to find multiple solutions for motor problems leading to develop the components of motor creativity represented by fluency, flexibility and originality (20).

\section{Research Problem:}

Through their experiences in teaching the course of motor expression to the four academic grades and their experience in the field of supervising female students of the field practice in the 3rd and 4th grades (teaching branch) at Faculty of Physical Education for girls, the two researchers noticed that female students (in both grades) had lower ability of motor creativity during preparing creative statements needed from them within the requirements of the college curriculum or artistic shows they asked to perform within items of evaluation of the field practice course.

During their follow-up of how female students design motor statements and the required creative shows, the two researchers noticed that most female students spent much time to compose a motor statement indicating that they had weak ability to produce new movements or regular motor configurations, as the objectives of teaching the motor expression curriculum to the four grades are to have female students acquire information and knowledge on fundamentals of designing motor expression displays (3).

As the enrichment activities play an important role in developing innovation and creativity, the two researchers decided to design a program containing enrichment activities for the 4th grade (teaching branch) including a great sort of motor skills in modern dance taught via irregular methods such as the discovery method, problem solving and training on motor improvisation in a step to increase the level of creativity and to improve the level of performance in motor expression aiming to training the girl on employing experiences acquired through her learning motor expression and making benefit from the same in the practical life.

\section{Research Objective:}

The objective of the current investigation was to design a suggested enrichment activity program and to know its effect on the following:

1. Creativity in motor expression with its components viz. fluency, flexibility and originality in female students in the 4th grade (teaching branch) at Faculty of Physical Education for girls, Cairo.

2. The level of performance in motor expression in female students in the 4th grade (teaching branch) at Faculty of Physical Education for female students, Cairo.

\section{Research Hypotheses:}

1. There are significant differences between the pre and post-measurements in the experimental group in creativity with its components and the level of performance in motor expression in favor of the post-measurement.

2. There are significant differences between the pre and post-measurements in the control group in creativity with its components and the level of performance in motor expression in favor of the post-measurement.

3. There are significant differences between the post-measurement in the experimental and control groups in creativity with its components and the level of performance in motor expression in favor of the experimental group.

\section{Research Procedures:}

\section{Method:}

The two researchers used the experimental method through the pre and post-measurement design of two groups representing an experimental and control groups to suit the nature of this research.

\section{Research people}

They were select intentionally from female students in the 4th grade (teaching branch) at 
Faculty of Physical Education for female students, Helwan University in (2011-2012) academic year in the 1 st academic term accounting (42) female students. Ten (10) female students were excluded as (6) female students were incommensurate with female students in the sample, (3) female students did not like to participate and an injured girl. Also (8) female students were selected for the pilot sample, hence, the final sample consisted of (24) female students who were equalized in the two groups in respect of (age, weight, height, intelligence, creativity in motor expression, the level of performance in motor expression) to adjust variables that may effect on dependant variables and all variables were insignificant.

\section{Tool of Collecting Data:}

The two researchers used the creativity test in motor expression prepared by Amal Morsi (1990) and they revised it in (2011) through interviewing a group of experts in the field of motor expression (attachment 1) and subtracting some measurements of (flexibility and motor originality) components on them. They selected measurements getting $80 \%$ of the expert opinions, consequently, the test consisted of three components; fluency (15 scores) of one measurement, flexibility (29 scores) of four measurements and originality (21scores) of three measurements and the total score of the test was (65). The high score of the test indicated the increase of ability of creativity in motor expression.

\section{Pilot Study:}

The two researchers conducted three studies to reach a test to measure creativity in motor expression to predict the range of its suitability to measure its purpose and to what extent the enrichment activities in the program were suitable for abilities of the sample and the possibility of carrying out such activities as illustrated below:

The 1st pilot study:

It aimed at getting a test to measure creativity in motor expression and the test of creativity in motor expression prepared by Amal Morsi (1990) was gotten and the researchers found that this test was in need of some revisions represented in the component of flexibility and originality through the employment of movement elements as the important role played by such elements in the process of creativity. The researcher suggested some measurements achieving this purpose which was presented to the experts in the field.

The 2nd pilot study:

It aimed at carrying out scientific treatments of the test of creativity in motor expression.

\section{Validity:}

The two researchers used the validity of differentiation between two groups representing differentiated and non-differentiated groups of (8) female students each. The results concluded that there were significant differences between the two groups in favor of the differentiated group in the test with its components under investigation at the rate of (3.338), (3.445), (4.427) and (3.403) for fluency, flexibility, originality and the total score of the test; respectively indicating that the test was valid in measuring what has been set for.

\section{Stability:}

To compute stability the two researchers used the test and re-test method on a rating sample of (8) female students. The results showed that there was a significant correlation coefficient between the 1 st and the 2nd applications of the test of creativity in motor expression with its components under investigation at the rate of (1.00), (1.00) , (0.157) and (0.317) for fluency, flexibility, originality and the total score of creativity; respectively indicating that the test used was stable.

The 3rd pilot study aiming at knowing the following:

1. The range of suitability of enrichment activities in the program for the ability of the sample.

2. Identifying difficulties that may arise during carrying out.

3. Outlining the suitable time for each unit in the program and time of each part.

The results illustrated the following:

1. Activities of the program were suitable and proper for the abilities of the sample.

2. There were no difficulties that might hinder the process of carrying out. 
3. Outlining the total time of the motor unit and time of each part.

\section{The suggested program:}

After surveying references and previous studies extensively, the two researchers have set the suggested program on the following scientific basis:

\section{Objective of the program:}

The purpose of the program was to develop creativity in the motor expression in female students in the 4th grade (teaching branch) through a sort of enrichment activities working on the following:

1. Providing them with a great motor collection via performing a various sort of motor displays of modern dance and viewing several modern dance displays through a compacted disc.

2. Motivating creative abilities in female students via motor improvisation with different stimulants.

3. Triggering the ability for creative product via employing motor elements in performing body positions, their derivatives and the basic movements with their different types by using discovery and problem solving methods.

\section{Time of carrying out the program:}

The program included a sort of enrichment activities and some other exercises applied within (24) training units distributed to (8) weeks at the rate of (3) units a week of (90) min. each making a total of (36) hrs. for the whole program (attachment 6). The unit was subdivided into three main sections.

\section{Introductory part (15 min.) containing two sub-sections:}

1. Warming up (5 min.): aiming at preparing and activating blood circulation and containing some exercises for all body parts.

2. Motor duties (10 $\mathrm{min})$, the "1st activity": Each girl should display a motor statement consisting of 8 counts and she selected it from some modern dance designs on a compacted disc that has been distributed to female students prior to the commencement of the program (self-learning).

\section{The main part (70 min.): containing 4 sections. \\ 1. The 1 st section (5 min.): (viewing).}

The motor section that will be taught to female students in the unit by computer is to be viewed. The two researchers explained skills and movements and discuss female students on how to employ movement elements.

2. The 2nd section (25 min.): "the 2nd activity"(performance)

Some skills and distinctive and expressed movements are trained and gained through the practical performance of the motor section that has been viewed by computer in the previous section.

3. The 3rd section: (20 min): "the 3rd activity" (performances of movements)

One or more elements of the movement are employed during performing different movements and skills by using the discovery and problem solving methods.

4. The 4th section (5 min.)(relaxation)

To calm the body and mind through relaxation and getting away from thinking of any source of anxiety together with closing eyes.

5. The 5th section (15 min.): "the 4th activity" (improvisation)

Female students should improvize freely (single, duple, group) by using different auditory, imaginary, emotional, motor and tool stimuli.

III. The final part (5 min.): It represents calming and relaxing exercises to leave good impression in the female students' hearts.

Teaching methods used:

- Practical presentation (example).

- Motor discovery.

- Solving problems.

- Self-learning.

\section{Research executive procedures Pre-measurement:}

It was carried out on the control and experimental groups from Tuesday, 4/10/2011 to Thursday, 6/10/2011 in all variables in respect of all research variables under investigation.

\section{Program application:}

The suggested program was applied to the experimental group from Sunday, 9/10/2011 to 
26/12/2011 at the rate of three units a weak on Mondays and Thursdays morning after the college day.

For the control group, female students were trained on the scheduled skills in the subject of motor expression being decided on this grade with the same hours equal to those scheduled in the suggested program. The two researchers supervized this training which was on Sundays in the morning, Mondays and Wednesdays after the college day.

\section{Post-measurement:}

After the suggested program was applied, the post-measurements have been conducted on the control and experimental groups from Tuesday, $27 / 12 / 2011$ to Thursday, 29/12/2011 in all variables under investigation. The postmeasurements were carried out similar to the method of applying the pre-measurements.

\section{Statistical methods used:}

The two researchers carried out statistical treatments by using the (SPSS) statistical package through the use of the Mann-Whitney test to find out the validity through differentiation between the distinctive and undistinctive groups and Wilcoxon Signed -Ranks test to find out stability by re-testing the single group (test \& re-test). The two researchers used this kind of tests as the research sample was small (24 female students) and such tests are valid for non-barometric statistics of small samples (less than 30 individuals).

\section{Results presentation:}

Table (1)

Significance of differences between the pre and post-measurements for the experimental and control groups in creativity in motor expression and its components

(Wilcoxon test) $\quad n=12$

\begin{tabular}{|c|c|c|c|c|c|c|c|}
\hline Variables & Items & $\begin{array}{l}\text { No .of } \\
\text { ranks }\end{array}$ & $\begin{array}{l}\text { Rank } \\
\text { mean }\end{array}$ & $\begin{array}{l}\text { Total } \\
\text { rank }\end{array}$ & $Z$ value & $\begin{array}{c}\text { Error } \\
\text { coefficient }\end{array}$ & Significance \\
\hline \multirow{4}{*}{ Fluency } & - Ranks & 0 & 0.00 & 0.00 & \multirow{4}{*}{3.088} & \multirow{4}{*}{0.002} & \multirow{4}{*}{$* \mathrm{~S}$} \\
\hline & + Ranks & 12 & 6.50 & 78.00 & & & \\
\hline & Correlation & $\mathbf{0}$ & & & & & \\
\hline & Total & 12 & & & & & \\
\hline \multirow{4}{*}{ flexibility } & - Ranks & 1 & 1.00 & 1.00 & \multirow{4}{*}{2.992} & \multirow{4}{*}{0.003} & \multirow{4}{*}{$* \mathbf{S}$} \\
\hline & + Ranks & 11 & 7.00 & 77.00 & & & \\
\hline & Correlation & $\mathbf{0}$ & & & & & \\
\hline & Total & 12 & & & & & \\
\hline \multirow{4}{*}{ Originality } & - Ranks & $\mathbf{0}$ & 0.00 & 0.00 & \multirow{4}{*}{3.077} & \multirow{4}{*}{0.002} & \multirow{4}{*}{$* \mathbf{S}$} \\
\hline & + Ranks & 12 & 6.50 & 78.00 & & & \\
\hline & Correlation & $\mathbf{0}$ & & & & & \\
\hline & Total & 12 & & & & & \\
\hline \multirow{4}{*}{$\begin{array}{l}\text { Creativity } \\
\text { total score }\end{array}$} & - Ranks & $\mathbf{0}$ & 0.00 & 0.00 & \multirow{4}{*}{3.066} & \multirow{4}{*}{0.002} & \multirow{4}{*}{$* \mathbf{S}$} \\
\hline & + Ranks & 12 & 6.50 & 78.00 & & & \\
\hline & Correlation & $\mathbf{0}$ & & & & & \\
\hline & Total & 12 & & & & & \\
\hline \multirow{4}{*}{$\begin{array}{l}\text { Performance } \\
\text { level }\end{array}$} & - Ranks & $\mathbf{0}$ & 0.00 & 0.00 & \multirow{4}{*}{3.062} & \multirow{4}{*}{0.002} & \multirow{4}{*}{$* \mathbf{S}$} \\
\hline & + Ranks & 12 & 6.50 & 78.00 & & & \\
\hline & Correlation & $\mathbf{0}$ & & & & & \\
\hline & Total & 12 & & & & & \\
\hline
\end{tabular}

Tabulated (Z) equals 1.96 at the significance level of .05

Data in Table (1) illustrate that there are significant differences between the pre and postmeasurements in the experimental group in favor of the post-measurement in motor creativity with its three components represented by fluency, flexibility and originality and the level of performance in motor expression. 
Table (2)

Significance of differences between the pre and post-measurements for the control group in creativity in motor expression and its components

(Wilcoxon test) $\quad n=12$

\begin{tabular}{|c|c|c|c|c|c|c|c|}
\hline Variables & Items & $\begin{array}{l}\text { No .of } \\
\text { ranks }\end{array}$ & $\begin{array}{l}\text { Rank } \\
\text { mean }\end{array}$ & $\begin{array}{l}\text { Total } \\
\text { rank }\end{array}$ & $Z$ value & $\begin{array}{c}\text { Error } \\
\text { coefficient }\end{array}$ & Significance \\
\hline \multirow{4}{*}{ Fluency } & - Ranks & 2 & 1.75 & 3.50 & \multirow{4}{*}{0.272} & \multirow{4}{*}{0.785} & \multirow{4}{*}{ N.S } \\
\hline & + Ranks & 1 & 2.50 & 2.50 & & & \\
\hline & Correlation & 9 & & & & & \\
\hline & Total & 12 & & & & & \\
\hline \multirow{4}{*}{ flexibility } & - Ranks & 1 & 1.50 & 1.50 & \multirow{4}{*}{$\mathbf{0}$} & \multirow{4}{*}{1.00} & \multirow{4}{*}{ N.S } \\
\hline & + Ranks & 1 & 1.50 & 1.50 & & & \\
\hline & Correlation & 10 & & & & & \\
\hline & Total & 12 & & & & & \\
\hline \multirow{4}{*}{ Originality } & - Ranks & 0 & 0.00 & 0.00 & \multirow{4}{*}{$\mathbf{0}$} & \multirow{4}{*}{1.00} & \multirow{4}{*}{ N.S } \\
\hline & + Ranks & 0 & 0.00 & 0.00 & & & \\
\hline & Correlation & 12 & & & & & \\
\hline & Total & 12 & & & & & \\
\hline \multirow{4}{*}{$\begin{array}{l}\text { Creativity } \\
\text { total score }\end{array}$} & - Ranks & 2 & 1.50 & 3.00 & \multirow{4}{*}{$\mathbf{0}$} & \multirow{4}{*}{1.00} & \multirow{4}{*}{ N.S } \\
\hline & + Ranks & 1 & 3.00 & 3.00 & & & \\
\hline & Correlation & 9 & & & & & \\
\hline & Total & 12 & & & & & \\
\hline \multirow{4}{*}{$\begin{array}{l}\text { Performance } \\
\text { level }\end{array}$} & - Ranks & 0 & 0.00 & 0.00 & \multirow{4}{*}{3.062} & \multirow{4}{*}{0.002} & \multirow{4}{*}{$\mathbf{S}^{*}$} \\
\hline & + Ranks & 12 & 6.50 & 78.00 & & & \\
\hline & Correlation & 0 & & & & & \\
\hline & Total & 12 & & & & & \\
\hline
\end{tabular}

Tabulated (Z) equals 1.96 at the significance level of .05

Data in Table (2) shows that there are no creativity with its three components and there significant differences between the pre and post- are significant differences in favor of the postmeasurements in the control group in motor measurement in the level of performance.

Table (3)

Significance of differences between the two post-measurements for the control and experimental groups in creativity in motor expression and its components

(Mann-Whitney Test)

\begin{tabular}{|c|c|c|c|c|c|c|c|}
\hline Variables & Groups & $\begin{array}{l}\text { No .of } \\
\text { ranks }\end{array}$ & $\begin{array}{l}\text { Rank } \\
\text { mean }\end{array}$ & $\begin{array}{l}\text { Total } \\
\text { rank }\end{array}$ & $\begin{array}{c}\text { Mann- } \\
\text { Whitney } \\
\text { Y }\end{array}$ & $Z$ value & Significance \\
\hline \multirow{3}{*}{ Fluency } & Control & 12 & 6.50 & 78.00 & \multirow{3}{*}{ 0 } & \multirow{3}{*}{4.210} & \multirow{3}{*}{$\mathbf{S}^{*}$} \\
\hline & Experimental & 12 & 18.50 & 222.00 & & & \\
\hline & Total & 24 & & & & & \\
\hline \multirow{3}{*}{ flexibility } & Control & 12 & 7.17 & 86.00 & \multirow{3}{*}{8.00} & \multirow{3}{*}{3.743} & \multirow{3}{*}{$\mathbf{S}^{*}$} \\
\hline & Experimental & 12 & 17.83 & 214.00 & & & \\
\hline & Total & 24 & & & & & \\
\hline \multirow{3}{*}{ Originality } & Control & 12 & 6.50 & 78.00 & \multirow{3}{*}{$\mathbf{0}$} & \multirow{3}{*}{4.216} & \multirow{3}{*}{$\mathbf{S}^{*}$} \\
\hline & Experimental & 12 & 18.50 & 222.00 & & & \\
\hline & Total & 24 & & & & & \\
\hline \multirow{3}{*}{$\begin{array}{l}\text { Creativity } \\
\text { total score }\end{array}$} & Control & 12 & 6.50 & 78.00 & \multirow{3}{*}{$\mathbf{0}$} & \multirow{3}{*}{4.180} & \multirow{3}{*}{$\mathbf{S}^{*}$} \\
\hline & Experimental & 12 & 18.50 & 222.00 & & & \\
\hline & Total & 24 & & & & & \\
\hline \multirow{3}{*}{$\begin{array}{c}\text { Performance } \\
\text { level }\end{array}$} & Control & 12 & 6.50 & 78.00 & \multirow{3}{*}{$\mathbf{0}$} & \multirow{3}{*}{4.167} & \multirow{3}{*}{$\mathbf{S}^{*}$} \\
\hline & Experimental & 12 & 18.50 & 222.00 & & & \\
\hline & Total & 24 & & & & & \\
\hline
\end{tabular}

Tabulated (Z) equals 1.96 at the significance level of .05 
Data in Table (3) reveal that there are significant differences between the two postmeasurements in the control and experimental groups in favor of the experimental group in creativity with its components and the level of performance in motor expression.

\section{Discussion of results:}

The significant differences between the pre and post-measurements in the experimental group that were in favor of the post-measurement in motor creativity with its three components represented by fluency, flexibility and originality and the level of performance in motor expression Table(1) could be attributed to the significant differences of fluency and flexibility. Also, it could be related to the nature of the suggested program that its vocabulary and different activities to suit the level of mental abilities of the sample under investigation through offering the enrichment activities that led to gain a great sort of skills and knowledge with interesting scientific method that comprised basic positions and their derivatives and basic movements of the modern dance with their types viz. transitive movements and stand performed movements. Also the knowledge of the research sample on the effective movement elements in performance and how to employ such elements in the motor statement through girl's using the space and her sense of the movement average and her abilities to concentrate and the use of different levels and directions. This was applied in motor performance section within each program unit which contained open questions needed several motor responses without standing on one response leading to enrich female students' experiences. Training female students on how to express their ideas and opinions in the shadow of numerous opinions and responses enable them to recall and to modify their knowledge in the light of the new knowledge they gained that helped female students develop creating movements derived from the basic positions (fluency) or free movements not restricted to a basic position with easy transition from a movement to another (flexibility). This approach agreed with that of Adel Abdulla Mohammed (2005) who indicated that the enrichment programs could increase the students' emotion towards creativity and they made them more open to experiences of others leading to generate several ideas. He mentioned also that the most important way to achieve the enrichment program was to add new, advanced, more difficult and compound skills (4).

Paulette Cote (1998) confirmed that the ability of the individual increased to select the suitable movement by increasing his motor experience and the basic knowledge needed with the exercise could effect on the creative ability of fluency and flexibility (16). For the significant differences of originality, the two researchers related these differences to the suggested program which included performance of some modern dance displays through which several, various and unique skills and movements could be gained in addition to the enrichment activity of the motor duties that increased the girl's outcome of various, unique and unfamiliar movements according to her sense and feelings. The girl also benefited from the enrichment activity of motor improvisation with numerous stimuli that furnished the female students with several chances to improvise new movements and various motor statements expressing the different stimuli whether this improvisation was single, duple or group that helped the girl create unique movements and perform the greatest number of various motor statements to express a stimulus or various stimuli and consequently, originality was improved. Added to this the suggested program contained different types of interesting music which was a co-factor for suspense and fun within the program units which assisted in brainstorming with the sample leading to positive effect on the motor creativity in female students. This finding was in conformity with those of Safiya Mohi El-Din (2007) who indicated that motor improvisation could increase imagination and develop imaginary ability leading to develop creativity (19). This finding also was in agreement with those of Weeping and Philip (2002) who stated that creativity and creative thinking in individuals could be developed and improved through exercise, practice, learning, furnishing chances and excited educational situations stimulating thinking and creation in the context of a program aiming at teaching the improvement of creation and its skills (20). The same finding was in line with those of Al- 
Shahili (2005) and Adel Abdulla (2005) who showed that the enrichment programs could help students actively treat problems through stirring up challenge and depth in ideas leading to develop creative thinking skills that enable students to present original alternatives in solving problems and they added that additional duties and activities were important ways to achieve the enrichment programs $(10,4)$. Similarly the finding tallied with the studies of Amal Sayed Morsi (1990) and Manal Mansour (2002) who mentioned that the ability of the individual to perform the greatest possible number of various unique motor statements to express several stimuli in limited time indicated that the individual had a high degree of motor originality $(5,12)$. The finding also agreed with the study of Leila Sharaf (2006) who showed that using motor improvisation programs with several stimuli and music in their content had positive effect on raising the level of motor creativity (11).

For the significant differences in the level of performance, the two researchers attributed them to the development of the girl's ability to create and freedom in expressing what inside her and discovering her inherent creative ability acquiring her higher self confidence that helped her perform movements more precisely and neatly. Continuous training on the effective motor elements on motor performance such as concentration during performance, girl's better using directions and the ability to use the space, levels and her sense of the suitable range of the movement in respect of strength and weakness and viewing different motor statements on the compacted discs helped the girl acquire a better motor example of different movements and skills and all these had positive effect on raising the level of performance in the sample under investigation. These findings were in harmony with the results of Manal Mansour (2002) who indicated that improving the ability of motor creativity could raise the level of motor performance (12).

From the foregoing it is clear that the differences in motor creativity and the performance level are significant and virtually achieving the first hypothesis that states" there are significant differences between the pre and post-measurements in the experimental group in creativity with its components and the level of performance in motor expression in favor of the post-measurement".

There are no significant differences between the pre and post-measurements in the control group in motor creativity with its three components and there are significant differences in favor of the post-measurement in the level of performance Table (2). The two researchers related that to the training on the scheduled curriculum that has been applied to this group with similar hours to those applied in the suggested program to the experimental group that greatly considered technical basis and motor technique as well as components that help raise the level of performance but the training neglected basis and elements that help develop the girl's ability to create. The two researchers viewed that the motor outcome the girl acquired through the scheduled curriculum was not sufficient to give the girl motor storage suitable for the creative situations facing the girl and this achieves the 2nd hypothesis that states "there are significant differences between the pre and post-measurements in the control group in creativity with its components and the level of performance in motor expression in favor of the post-measurement".

In the view of the two researchers, the control group has trained on the scheduled course with a number of hours equal to that of the suggested program. However, the results do not show any significance indicating that the creativity as whole or any of its components is improved as a result of the comprehensive training on the contents of the scheduled curriculum. This finding may be related to the specific section of improving creativity in this curriculum viz. modern dance is not taught on purpose to develop creativity but to acquire skills and modern dance movements and some theoretical information on creativity because of the narrow time to teach this section. Consequently, female students get informed of some types of techniques and some movements without training on how to create and to develop creative abilities within them, despite positive differences shown by this group in the level of performance that could be related to training on the scheduled curriculum but considered slight 
improvement as compared with that in the experimental group.

The results revealed that that there were significant differences between the two postmeasurements in the control and experimental groups in favor of the experimental group in creativity with its components and the level of performance in motor expression Table (3). The two researchers attributed the superiority of the experimental group in the level of performance to the suggested program with its content of different enrichment activities included basis and skills gave a chance to the girl to create and to output her potentials and abilities shown in a single activity through the motor performance activity or in duple or group activities through the improvisation activity where female students have been divided to work in duple or in groups leading to increase the reaction between female students which gave an active learning environment that contributed to stimulate thinking through generating suitable solutions for educational situation that helped develop creativity. This finding was in agreement with that of Ismaeil Abdel Fattah (2003) who indicated that cooperation between two persons could lead to create as people could share their creative opinions through cooperation (8). This finding tallied with studies of Abdulla Mostafa (2006) and Mohammed Bin Abdel Aziz (2011) who illustrated the great role of the enrichment programs in developing skills of creativity and innovation in the girl. The two researchers viewed that enriching the suggested program with performing compound and new modern dance displays with the recorded various and interesting music and viewing different motor statements on computer could have great effect on stimulating female students' enthusiasm and motivating creative abilities to trigger towards expressing self's deposits and the development of such creative abilities could have effect on raising the level of performance in motor expression with an indirect way $(2,14)$. This finding agreed with that of Mohabbat Abu Amira (2000) who indicated that the enrichment material was distinct from that of the scheduled curriculum with two dimensions, firstly widening dimension that to present new subjects but related to the course and the secondly depth dimension that to consider the curriculum and to give more insight leading to creative and innovative thinking in students (13). Also, this finding was in line with that of Refaat Bahjan (2005) who postulated that to ensure the success of the enrichment program restrictions must have been outlined such as the girl's desire, availability of time for execution and finding the specialized supervisor and these restrictions were provided in the suggested program that helped develop creativity and improve the level of performance in motor expression (17). The agreement of this finding was extended to the results of the study of Riham Ahmed Hosni (2005) who showed the positive effect of performing ballet designs and motor items on developing imagination of students to create distinct motor formations and statements. The finding also agreed with the study results of Hazem Ahmed Mohammed (2010) who illustrated the positive effect of performing displays of group exercises on motor creativity and its components. It also agreed with the study of Khaled Abdulla (2009) who pointed to the positive effect of the enrichment activities on creative thinking (18), (7), (9). Hence, the 3rd hypothesis is achieved and that states "there are significant differences in the experimental and control groups in creativity with its components and the level of performance in motor expression in favor of the experimental group".

\section{Conclusions:}

On the basis of the statistical treatments and their results the two researchers concluded the following:

1. The suggested enrichment program had positive effect on developing creativity in motor expression with its three components viz. fluency, flexibility and originality that could contribute to increase the ability of female students to produce new movements or regulated motor formations and to design technical creative displays in least possible time, consequently, the effectiveness of the role of female students in the 4th grade (teaching branch) in the practical life could be increased. Hence, the objectives of teaching motor expression curriculum could be achieved.

2. The suggested enrichment program had positive effect on improving the level of 
performance in motor expression that could help the college female students better perform their role in the practical life.

3. The experimental group was superior to the control group in creativity and the level of performance in motor expression indicating the importance of making benefits from enrichment activities.

\section{Recommendations:}

1. The program used in this study should be included in the curriculum of motor expression for the 4th grade (teaching branch) as the results showed that the program was greatly positive.

2. Benefiting from the suggested program to develop creativity in motor expression in female students at Faculty of Physical Education.

3. Making programs similar to the suggested program for the other college grades.

4. Similar researches should be carried out to develop motor creativity in the other sports activities.

5. Considering the use of some assisting means such as computer to give female students more practical experiences and to increase references and the ability of motor visualization and creativity.

\section{References:}

1. Abdel Radhi Hassan Al-Maraghi: Application of Educational Quality Assurance System and Dependence to Develop Academic and Preacademic Education. Arab Thought House, Cairo, 2008.

2. Abdulla Mostafa Mahmoud Gradat (2006): The effect of an enrichment program standing on problems on developing critical and creative thinking skills in superior students at pioneer centers in Jordan. Ph. D. Thesis unpublished, Amman Arab University for Graduate Studies.

3. Academic Guide for Dept. of Motor expression and Rhythm Training in Bachelor Stage. Faculty of Physical Education for Female students, Helwan University 2010-2011.

4. Adel Abdulla Mohammed: Psychology of Talent. Arab Rashad House, Cairo, 2005.
5. Amal Sayed Morsi: "The Effect of the Recorded Music on Developing Creativity in Motor expression and its Relation with the Level of Performance". Ph. D. Thesis Unpublished, Faculty of Physical Education for Female students, Cairo, 1990.

6. Greenfield, M. (2007): Leaders or learning, a multiple case study of the future role of faculty in high of education "Doctor al Dissenshion, Capelle University".

7. Hazem Ahmed Mohammed Al-Sayed: "The Effect of Displays of Group Exercises on some Factors of Motor Creativity and Harmonic Abilities in Students at Faculty of Physical Education, Master Thesis Unpublished, Mansoura University, 2010.

8. Ismaeil Abdel Fattah: Creativity and Its Development in Children. Arab Book House, Cairo, 2003.

9. Khaled Abdulla Al-Hamouri (2009): The effect of an enrichment program in environmental education on developing creative thinking skills and attainment in gifted students in Al-Qassim region. Journal of Islamic University (Human Studies Series), Vol. 17, AlQassim University, The Kingdom of Saudi Arabia.

10. Khaled Khalil Al-Shahili: Gifted Superior Children. University Book House, Al-Ain, Emirates, 2005.

11. Leila Sharaf Al-Din Emam Hassan (2006): Motor improvisation by using multiple stimuli and its effect on motor creativity and some psychological variables. Ph. D. Thesis unpublished, Faculty of Physical Education for Female students, Helwan University.

12. Manal Mohammed Sayed Mansour (2002): The effect of developing fluency and motor originality on creativity in modern dance. Ph. D. Thesis unpublished, Faculty of Physical Education for Female students, Zagazig University.

13. Mohabbat Abu Amira: The Superiors and Female Athletes - Applied Studies. Arab Book House Library, Cairo (2000).

14. Mohammed Bin Abdel Aziz Al-Auqil (2011): The effect of using suggested enrichment scientific activities and developing 
integrative science processes and creative thinking in talented pupils in the primary stage. $\mathrm{Ph}$. D. Thesis unpublished, Faculty of Education, King Saud University.

15. Mohammed Jihad Al-Gamal: Developing Creative Thinking Skills. Academic Book House, Al-Ain, The United Arab Emirates, 2005.

16. Paulette Cote, L. (1998): The effect of experience creativity in dance. Research Quarterly for Exercise and Sport, Vol. 69, No. 1, March.

17. Refaat Mahmoud Bahjan: Enrichment and Critical Thinking (An Experimental Study with Superior Students in Primary Education), Book World, Cairo, 2005.
18. Riham Ahmed Ehab (2005): Using ballet designs to develop the ability of the student to design expressive skills, Master Thesis unpublished, Faculty of Music Education, Helwan University, Cairo.

19. Safiya Ahmed Mohi Al-Din: Creative Design of Motor expression Displays" Movement Elements, ImprovisationTheatricalization". Anglo-Egyptian Library, Cairo, 2007.

20. Safiya Ahmed Mohi Al-Din and Samia Rabie Mohammed: Ballet and Modern Dance. Publication Book Center, Cairo, 2005.

21. Weeping, H. S. \& Philip, A. (2002): Scientific education reform. Journal of Education, 47, (14), 389-403. 